\title{
IMPULSE OSCILLOMETRIC EVALUATION OF AIRWAY RESISTANCE IN OVERWEIGHT AND OBESE CHILDREN WITH ASTHMA
}

\author{
Arzu Caliskan Polat ${ }^{1}$, Hasan Yuksel ${ }^{2}$, Adem Yasar $^{1}$, and Ozge Yilmaz ${ }^{2}$ \\ ${ }^{1}$ Celal Bayar University School of Medicine \\ ${ }^{2}$ Celal Bayar University
}

August 11, 2020

\begin{abstract}
Background: Change in airway resistance and inflammation are the two most commonly accused pathogenetic processes in the coexistence of asthma and obesity. The aim of this study was to compare airway resistance between normal weight and overweight/obese children using impulse oscillometry (IOS). Methods: We consecutively enrolled 3 to 10-year-old children with asthma who presented to our department between May and August 2018. Ones with a body mass index percentile at or above 85th percentile were grouped as overweight/obese. Sociodemographic characteristics such as age, sex and family history of allergy were recorded and Test for Respiratory and Asthma Control in Kids (TRACK) was filled in for all. Finally, impulse oscillometric (IOS) measurements were taken. Results: We enrolled 170 subjects; among which 114 (67.1\%) were normal weight while 56 (33\%) were overweight/obese. Sociodemographic characteristics were not significantly different between the two groups, but asthma control was significantly worse in the overweight/obese group $(75.9 \pm 21.1$ vs $85.9 \pm 17.8, \mathrm{p}=0.001)$. Impulse oscillometric measurements of resistance and reactance were nor significantly different between the two groups. Conclusion: Asthma control in children who are overweight or obese are worse compared to the normal weight ones but, airway resistance and reactance measured by IOS at different frequencies are not significantly different between these two groups. This implies that airway resistance change may not the main pathogenetic mechanism underlying the uncontrolled asthma and obesity coexistence.
\end{abstract}

\section{INTRODUCTION}

Obesity and asthma commonly co-exist in children and obesity is related to more severe asthma as well as deteriorated spirometric indices such as FEV1 ${ }^{1,2}$. Cottrell et al have reported that asthma prevalence shows a parallel increase with body mass index (BMI) indices ${ }^{3}$. Moreover, a prospective study in school age children demonstrated that asthma prevalence increases with obesity ${ }^{4}$. There are many theories that explain this co-existence; mechanical influences of obesity on the airway as depicted by the decreased FEV1 as mentioned above, chronic inflammation due to increased leptin and oxidative stress in obesity, hormonal changes such as decreased progesterone leading to blunted beta-2 receptor response in obese individuals and co-morbid conditions such as obesity ${ }^{5}$.

Impulse oscillometry (IOS) is a method that allows passive measurement of the airway mechanics of the airways by using sound waves. The technique does not require cooperation and the measurements are taken during tidal breathing. Airway resistance at different sound frequencies measure different parts of the airway. Measurements at low frequencies reflects both the central and peripheral airways while measurement at higher frequencies reflect the larger airways thus allowing prediction of the resistance and reactance of the small airways which are known to be primary area of involvement in asthma ${ }^{6,7}$.

The aim of this study was to compare airway resistance between normal weight and overweight/obese children 
using IOS.

\section{MATERIALS AND METHODS}

Study Design and Ethics

This cross-sectional study was approved by the Institutional Review Board of our University (number: 85252386-050.04.04). Informed consent was signed by all the parents.

\section{Study Population}

Asthmatic children aged three to 10 years, who presented to our clinic were enrolled consecutively. Asthma was diagnosed according to GINA guidelines with recurrent bronchial obstruction findings and clinical or lung function test reversibility with inhaled bronchodilator treatment ${ }^{8}$.

Inclusion Criteria were 1) age three to 10 years 2) diagnosed or followed up with asthma 3) no bronchodilator use during the last one week. Exclusion criteria were 1) asthma exacerbation during the last one week 2) diagnosis of CF, immunodeficiency or bronchiectasis that may change lung function tests 3) premature birth.

Sample size was calculated based on the $\mathrm{R}$ values of the IOS measurements; We expected to have a 1:3 ratio of overweight: normal weight ratio in the group, when we predicted a standard deviation (SD) of 0.2 and minimal effect size of 0.1 , the sample size required was 168 to get a power of $80 \%$.

\section{Data Collection}

Sociodemographic characteristics (age and sex), duration of asthma symptoms, allergic sensitization to inhalant allergens, number of asthma exacerbations in the past year, use of inhaled steroids, smoking history among the family members, family history of allergic diseases were recorded. Body weight and height measurements were undertaken at presentation as well as IOS measurements. Test for Respiratory and Asthma Control in Kids (TRACK) scores were recorded.

Skin Prick Testing For Inhalant Allergens

Skin prick tests were performed with Dermatophagoides Farinae, Dermatophagoides Pteron, Alternaria Tenius, Cat Epithelium, Olea, Plantago Lanceolata, Grasses Mix and Küchenschabe (Allergopharma, Germany). A positive control (histamine $10 \mathrm{mg} / \mathrm{ml}$ Allergopharma, Germany) and a negative (saline) control according to EAACI guidelines ${ }^{9}$.

Body Weight and Height Measurements

Body weights were measured with a digital scale and lengths were measured with a stadiometer (Seca, Germany) that can measure between 80-200 cm. During weight measurement, clothes and shoes were removed and shoes were removed during height measurement. Weight and height were measured by the pulmonary function test nurse. CDC Growth Tables percentile grouping was used to evaluate the length and body weight of the cases and the BMI percentages. Overweight and obese were defined as BMI over $85 \%$ and $95 \%$ respectively ${ }^{10}$.

Impulse Oscillometric Measurements

Airway resistance measurements were performed with the Jager MasterScreen-IOS system (Jaeger Co, Wurzberg, Germany). The patients were seated and rested 15 minutes before the test. They were told to hold the mouthpiece between their teeth and seal their lips around it tightly. Then they breathed calmly through the mouthpiece and bacterial filter attached to the pneumotograph. Measurements were made while the patients were in a sitting position, necks slightly extended. The subjects wore a nose clip and their cheeks were supported by the parents. Several breathing cycles that lasted for at least 30 seconds were recorded ${ }^{11}$. Three acceptable measurements were obtained for each subject and the mean of the values were taken.

Airway resistance $(\mathrm{R} /$ resistance) and elasticity capacity (X / reactance) are are measured at difference frequencies and resistance (R5, R10, R15) and reactance (X5, X10, X15) values were recorded at frequencies 
of $5,10,15$ and $20 \mathrm{~Hz}$.

Test for Respiratory and Asthma Control in Kids

Test for Respiratory and Asthma Control in Kids (TRACK) was used to measure the asthma control. It includes five items; frequency of symptoms during the past four weeks, nighttime awakenings due to symptoms and activity limitation, bronchodilator use during the last three months, and oral corticosteroid use during the past year. The score of each item ranges from 0-20 and the sum of these five scores gives the total score. High scores indicate good disease control, while scores below 80 indicate potential breathing problems and shall warn physicians ${ }^{12}$.

Statistical Analysis

Continuous variables such as age, resistance and reactance values of IOS measurement and TRACK scores were summarized as mean \pm standard deviation (SD) while categorical variables such as gender, family histories or allergic diseases and smoking were summarized as frequencies. Chi-square test was used to compare categoric variables and Mann Whitney U test was used to compare continuous variables between overweight and normal weight groups Statistical significance was defined as $\mathrm{p}<0.05$.

\section{RESULTS}

\section{Sociodemographic and Clinical Characteristics}

We enrolled 170 consecutive subjects with asthma aged three to 10 who presented to our clinic. Among these, $114(67.1 \%)$ were of normal body weight while $56(33 \%)$ were found to be overweight or obese. No statistically significant difference was observed between sociodemographic characteristics such as age, sex, gestational age at birth and birth weight $(\mathrm{p}=0.64, \mathrm{p}=0.62, \mathrm{p}=0.36, \mathrm{p}=0.58$ respectively) (Table 1$)$.

Family history was remarkable for allergic diseases in $67,5 \%$ of the normal weight and $62.5 \%$ of the overweight/obese group $(\mathrm{p}=0.51)$. Smoking history among the family members was not significantly different among the groups $(61.1 \%$ in the normal weight vs $60.7 \%$ in the overweight/obese, $\mathrm{p}=0.96)$.

\section{Clinical Characteristics}

Among the normal weight and overweight/obese groups, frequency of inhalant allergen sensitization was detected in $23.3 . \%$ and $21.6 \%$ respectively $(\mathrm{p}=0.84)$. The unplanned hospital admission due to asthma exacerbation in the previous year was found to be $2.1 \pm 2.5$ in the normal weight and $2.3 \pm 2.4$ in the overweight/obese groups $(\mathrm{p}=0.59)$. Use of inhaled steroids at presentation were not significantly different between the groups (91.2\% in the normal weight and $94.6 \%$ in the overweight/obese groups respectively, $\mathrm{p}=0.54)$. TRACK scores were significantly lower in the overweight/obese group compared to the normal weight group ( $75.9 \pm 21.1$ vs $85.9 \pm 17.8, \mathrm{p}=0.001)$ (Table 1 ).

Impulse Oscillometry Results

Resistance measurements in the two groups at frequencies 5,10,15 and 20 were not significantly different between the two groups $(\mathrm{p}=0.84, \mathrm{p}=0.84, \mathrm{p}=0.86, \mathrm{p}=0.90$ respectively). Similarly, reactance measurements did not different between the groups $(\mathrm{p}=0.29, \mathrm{p}=0.41, \mathrm{p}=0.59, \mathrm{p}=0.86$ respectively) (Table 2 ).

\section{DISCUSSION}

The results of our study confirm the findings of previous studies that showed worse asthma control in children who are overweight or obese compared to normal weight ones ${ }^{13-17}$. On the other hand, airway resistance and reactance measured by IOS were not found to be significantly different between these two groups suggesting a mechanism apart from airway resistance or caliber underlying the influence of obesity on asthma control.

Epidemiological studies have shown that obesity itself has a significant effect on respiratory function, and some suggest that obesity is a risk factor for development of asthma ${ }^{13}$. While body mass index (BMI) has been shown to have little effect on spirometry results, expiratory reserve volume and functional capacity are decreased in obese people compared to normal weight people. Body mass index (BMI) has been shown to 
be negatively related to various lung volume measurements ${ }^{14}$. However, the relationship between overweight and lung function in children is less clear despite observation of increased FVC and FEV1 in overweight and obese children ${ }^{15,16}$. More recently, the aggregation of various cohorts from healthy and asthmatic children and adolescents has confirmed that overweight or obesity is linked to higher than initial FVC, TLC and FEV1 and decreasing maximum flows and FEV1 $/ \mathrm{FVC}^{17}$. In our study, we wanted to show the effect of obesity on pulmonary resistance in asthmatic children. There are many studies investigating the effect of obesity on spirometry in asthmatic children, but patient compliance is required for spirometry and interpretation may be difficult in younger children. Therefore, we measured airway resistance by IOS that is a tidal breathing method not requiring compliance, thus, allowing enrollment of younger children. We found that the differences shown by spirometry in older age groups were not present in resistance and reactance values measured by IOS. IOS measures airway impedance, which is a function of resistance and reactance, thus predicts about the peripheral airway obstruction and detects inspiratory and expiratory changes in airway resistance in asthmatic children ${ }^{7,18,19}$.

In adults, IOS was found to be correlated with spirometry results but was not found to be correlated with asthma control ${ }^{20}$. Measurements of $\mathrm{R} 5 \mathrm{~Hz}$ and $\mathrm{AX}$ have been found to be more sensitive to bronchodilator response compared to FEV1 values in children ${ }^{21}$. Similarly, in our study asthma control was significantly worse in overweight/obese children but this was not reflected on the IOS measurements of resistence.

Obesity is associated with more severe asthma symptoms, poorer asthma control and poorer response to asthma treatment. This has been attributed to many factors including but not limited to increased oxidative stress, chronic inflammation and endothelial dysfunction ${ }^{22-24}$. Similar to these previous researches, our results confirmed that asthma control is worse in overweight/obese children compared to normal weight ones.

Family history of allergic diseases is a well-known independent risk factor for development of asthma in the child $^{8,25}$. In our study, family history of allergic diseases or asthma was not significantly different between normal weight and overweight/obese children. Lucas et al reported a higher rate of allergic sensitization in obese children with asthma compared to normal weight ones ${ }^{26}$. However, we did not detect a significant difference in the rate of allergic sensitization in normal weight and overweight/obese children suggesting that the association between body weight and asthma is beyond increased inflammation related to obesity. This difference might be related to the enrollement of overweight subjects as well obese subjects in our study.

Major limitation of this study is the lack of IOS normal for our population that precluded us from interpreting the deviation of the two groups from normal. However, since we aimed to evaluate the effect of being overweight or obese on airway resistance in asthma, we chose to compare overweight and normal weight asthmatic children with each other. The second limitation is the cross-sectional design which precluded us from seeing the change in resistance with change in time and weight.

One of the strengths of our study was the enrollment of young children, by the use of a tidal breathing method, IOS, to measure airway resistance and reactance. IOS is a reliable method in young children who can't perform spirometry. Moreover, resistance and reactance measurements at different frequencies allowed us to interpret about different parts of the airways.

In conclusion, asthma control in children who are overweight or obese are worse compared to the normal weight ones but, airway resistance and reactance measured by IOS at different frequencies are not significantly different between these two groups. This implies that airway resistance change may not be the main pathogenetic mechanism underlying the uncontrolled asthma and obesity coexistence. Further cohort studies, looking at the change in resistance values with age and body mass index in children will provide further insight about the relationship of obesity and airway resistance in asthmatic children.

\section{IMPACT STATEMENT}

Asthma control is worse in overweight and obese children, but this is not related to changes in airways resistance. This finding prompts further research on inflammatory profiles in these children.

\section{REFERENCES}


1. Peters U, Dixon AE, Forno E. Obesity and asthma. J Allergy Clin Immunol . 2018;141:1169-1179.

2. Beuther DA, Sutherland ER. Overweight, obesity, and incident asthma: a meta-analysis of prospective epidemiologic studies. Am J Respir Crit Care Med 2007;175:661-6.

3. Cottrell L, Neal WA, Ice C, Perez MK, Piedimonte G. Metabolic abnormalities in children with asthma. Am J Respir Crit Care Med 2011;183:441-8.

4. Gilliland FD, Berhane K, Islam T, McConnell R, Gauderman WJ, Gilliland SS, Avol E, Peters JM. Obesity and the risk of newly diagnosed asthma in school-age children. Am J Epidemiol 2003;158:40615.

5. Ali Z, Ulrik CS. Obesity and asthma: a coincidence or a causal relationship? A systematic review. Respir Med 2013;107:1287-300.

6. Bickel S, Popler J, Lesnick B, Eid N. Impulse oscillometry: Interpretation and practical applications. Chest. 2014;146:841-7.

7. Diaz Palacios MA, Hervas Marin D, Giner Valero A, Colomer Hernandez N, Toran Barona C, Hernandez Fernandez de Rojas D. Correlation between impulse oscillometry parameters and asthma control in an adult population. J Asthma Allergy . 2019;12:195-203.

8. https://ginasthma.org/wp-content/uploads/2020/04/GINA-2020-full-report_-final__wms.pdf) (accessed on April 25, 2020)

9. Bousquet J, Heinzerling L, Bachert C, Papadopoulos NG, Bousquet PJ, Burney PG, Canonica GW, Carlsen KH, Cox L, Haahtela T, Lodrup Carlsen KC, Price D, Samolinski B, Simons FE, Wickman M, Annesi-Maesano I, Baena-Cagnani CE, Bergmann KC, Bindslev-Jensen C, Casale TB, Chiriac A, Cruz AA, Dubakiene R, Durham SR, Fokkens WJ, Gerth-van-Wijk R, Kalayci O, Kowalski ML, Mari A, Mullol J, Nazamova-Baranova L, O'Hehir RE, Ohta K, Panzner P, Passalacqua G, Ring J, Rogala B, Romano A, Ryan D, Schmid-Grendelmeier P, Todo-Bom A, Valenta R, Woehrl S, Yusuf OM, Zuberbier T, Demoly P; Global Allergy and Asthma European Network; Allergic Rhinitis and its Impact on Asthma. Practical guide to skin prick tests in allergy to aeroallergens. Allergy. 2012;67:18-24.

10. Kuczmarski RJ, Ogden C, Grummer-Strawn L, et al. CDC Growth Charts: United States. Advance Data Report No. 314. Vital and Health Statistics of the Centers for Disease Control and Prevention, National Center for Health Statistics, 2000

11. Beydon N, Davis SD, Lombardi E, Allen JL, Arets HG, Aurora P, Bisgaard H, Davis GM, Ducharme FM, Eigen H, Gappa M, Gaultier C, Gustafsson PM, Hall GL, Hantos Z, Healy MJ, Jones MH, Klug B, Lodrup Carlsen KC, McKenzie SA, Marchal F, Mayer OH, Merkus PJ, Morris MG, Oostveen E, Pillow JJ, Seddon PC, Silverman M, Sly PD, Stocks J, Tepper RS, Vilozni D, Wilson NM; American Thoracic Society/European Respiratory Society Working Group on Infant and Young Children Pulmonary Function Testing. An official American Thoracic Society/European Respiratory Society statement: pulmonary function testing in preschool children. Am J Respir Crit Care Med. 2007;175:1304-45.

12. Yilmaz O, Turkeli A, Sahin S, Yuksel H. Predictive Value of the TRACK Questionnaire as a Measure of Asthma Control in Preschool Aged Children. Allergy Asthma Immunol Res. 2014;6:357-61.

13. Van Cleave J, Gortmaker SL, Perrin JM. Dynamics of obesity and chronic health conditions among children and youth. JAMA. 2010;303:623-30.

14. Brazzale DJ, Pretto JJ, Schachter LM. Optimizing respiratory function assessments to elucidate the impact of obesity on respiratory health. Respirology. 2015;20:715-21

15. Jones RL, Nzekwu M-MU. The effects of body mass index on lung volumes. Chest. 2006;130:827-33.

16. Ulger Z, Demir E, Tanac R, Gokşen D, Gülen F, Darcan S, Can D, Coker M. The effect of childhood obesity on respiratory function tests and airway hyperresponsiveness. Turk J Pediatr. 2006;48:43-50.

17. Forno E, Weiner DJ, Mullen J, Sawicki G, Kurland G, Han YY, Cloutier MM, Canino G, Weiss ST, Litonjua AA, Celedón JC. Obesity and Airway Dysanapsis in Children with and without Asthma. Am J Respir Crit Care Med. 2017;195:314-323.

18. Galant SP, Komarow HD, Shin HW, Siddiqui S, Lipworth BJ. The case for impulse oscillometry in the management of asthma in children and adults. Ann Allergy Asthma Immunol. 2017;118:664-671.

19. Sol IS, Kim YH, Kim S, Kim JD, Choi SH, Kim KW, Sohn MH. Assessment of within-breath impulse oscillometry parameters in children with asthma. Pediatr Pulmonol. 2019;54:117-124. 
20. McDowell KM. Recent Diagnosis Techniques in Pediatric Asthma: Impulse Oscillometry in Preschool Asthma and Use of Exhaled Nitric Oxide. Immunol Allergy Clin North Am. 2019;39:205-219.

21. Mondal P, Yirinec A, Midya V, Sankoorikal BJ, Smink G, Khokhar A, Abu-Hasan M, Bascom R. Diagnostic value of spirometry vs impulse oscillometry: A comparative study in children with sickle cell disease. Pediatr Pulmonol. 2019;54:1422-1430.

22. Manna P, Jain SK. Obesity, oxidative stress, adipose tissue dysfunction, and the associated health risks: causes and therapeutic strategies. Metab Syndr Relat Disord 2015;13:423e44.

23. Adcock IM, Cosio B, Tsaprouni L, Barnes PJ, Ito K. Redox regulation of histone deacetylases and glucocorticoid-mediated inhibition of the inflammatory response. Antioxid Redox Signal. 2005;7:14452.

24. Sivapalan P, Diamant Z, Ulrik CS. Obesity and asthma: current knowledge and future needs. Curr Opin Pulm Med. 2015;21:80-5.

25. London SJ, James Gauderman W, Avol E, Rappaport EB, Peters JM. Family history and the risk of early-onset persistent, early-onset transient, and late-onset asthma. Epidemiology. 2001;12:577-83.

26. Lucas JA, Moonie S, Olsen-Wilson K, Hogan MB. Asthma, allergy, and obesity: Examining the relationship among Nevada children. J Asthma. 2017;54:594-599.

Table 1. Sociodemographic and clinical characteristics of the study population grouped according to the body mass index (BMI) percentile

\begin{tabular}{|c|c|c|c|c|}
\hline & $\begin{array}{l}\mathrm{BMI}<85 \mathrm{P} \\
\mathrm{N}=114\end{array}$ & $\mathrm{BMI}[?] 85 \mathrm{p} \mathrm{N}=56$ & $\mathrm{p}$ & $95 \% \mathrm{CI}^{*}$ \\
\hline Age $* *$ & $81.8 \pm 18.9$ & $80.2 \pm 25.1$ & $0.64^{* * * *}$ & $-5.1-8.4$ \\
\hline $\begin{array}{l}\text { Birth wieght } \\
\text { (grams)** }\end{array}$ & $3201.9 \pm 636.4$ & $3260.9 \pm 675.3$ & $0.58^{* * * *}$ & $-268.5-150.6$ \\
\hline Gestational age** & $38.1 \pm 2.3$ & $38.4 \pm 2.1$ & $0.36^{* * * *}$ & $-1.0-0.4$ \\
\hline $\begin{array}{l}\text { Age at asthma } \\
\text { diagnosis** }\end{array}$ & $4.0 \pm 2.2$ & $3.8 \pm 2.1$ & $0.58^{* * * *}$ & $-0.51-0.89$ \\
\hline $\begin{array}{l}\text { Asthma control } \\
\text { test score** }\end{array}$ & $85.9 \pm 17.8$ & $75.9 \pm 21.1$ & $0.001^{* * * *}$ & $3.9-16.1$ \\
\hline $\begin{array}{l}\text { Birth type } \\
(\mathrm{C} / \mathrm{S})^{* * *}\end{array}$ & $65(57.5)$ & $41(73.2)$ & $0.06^{* * * * *}$ & \\
\hline Sex $(\text { Male })^{* * *}$ & $64(56.1)$ & $34(60.7)$ & $0.62^{* * * * *}$ & \\
\hline
\end{tabular}

$* 95 \%$ confidence interval of the difference

${ }^{* *}$ Expressed as mean \pm standard deviation

$* * *$ Expressed as frequency(column percentage)

****'Student's t test

******Fisher's exact test

Table 2. Impulse oscillometry (IOS) measurement results of the study populaiton grouped according to the body mass index (BMI) percentile

\begin{tabular}{lllll}
\hline IOS & $\mathbf{B M I}<\mathbf{8 5} \mathbf{P}$ & & & \\
Measurements* & $\mathbf{N = 1 1 4}$ & $\mathbf{B M I}[\mathbf{?}] \mathbf{8 5 p} \mathbf{~ N = 5 6}$ & $\mathbf{P * *}$ & $\mathbf{9 5 \% \mathbf { C I } * *}$ \\
\hline Z5 & $1.16 \pm 0.26$ & $1.18 \pm 0.25$ & 0.58 & $-0.11-0.06$ \\
AX & $2.58 \pm 1.36$ & $2.58 \pm 0.96$ & 0.96 & $-0.41-0.39$ \\
R5 & $1.12 \pm 0.26$ & $1.13 \pm 0.20$ & 0.84 & $-0.08-0.07$
\end{tabular}




\begin{tabular}{lllll}
\hline IOS & $\mathbf{B M I}<\mathbf{8 5} \mathbf{P}$ & & & \\
Measurements* & $\mathbf{N}=\mathbf{1 1 4}$ & $\mathbf{B M I}[\mathbf{?}] \mathbf{8 5} \mathbf{p} \mathbf{N}=\mathbf{5 6}$ & $\mathbf{P}^{* *}$ & $\mathbf{9 5 \% \mathbf { C I }}$ *** \\
\hline X5 & $-0.19 \pm 0.17$ & $-0.22-0.14$ & 0.29 & $-0.02-0.08$ \\
R10 & $0.94 \pm 0.18$ & $0.94-0.17$ & 0.84 & $-0.06-0.05$ \\
X10 & $-0.19 \pm 0.10$ & $-0.20-0.07$ & 0.41 & $-0.01-0.04$ \\
R15 & $0.86 \pm 0.16$ & $0.86-0.16$ & 0.86 & $-0.05-0.06$ \\
X15 & $-0.14 \pm 0.08$ & $-0.14-0.06$ & 0.59 & $-0.02-0.03$ \\
R20 & $0.78 \pm 0.15$ & $0.78-0.18$ & 0.90 & $-0.05-0.05$ \\
X20 & $-0.05 \pm 0.06$ & $-0.05-0.04$ & 0.86 & $-0.02-0.02$ \\
\hline
\end{tabular}

*Expressed as mean \pm standard deviation

**Student's t test

$* * * 95 \%$ confidence interval of the difference 